\title{
Judgment and Analysis in Oil Spill Risk Assessment
}

\author{
Thomas R. Stewart ${ }^{1}$ and Thomas M. Leschine ${ }^{2}$
}

Received January 2, 1985; revised June 17, 1985

\begin{abstract}
The risk of oil spills is a major environmental issue in the siting of proposed coastal refineries, oil terminals, deepwater ports, and in the leasing of offshore lands for oil exploration and development. As with any kind of risk, oil spill risk assessment is inherently judgmental and no analytic method can eliminate the need for judgment. This paper compares representative examples of oil spill risk assessments with regard to decisions about data, variables, functional relations, and uncertainty. The comparison emphasizes the judgmental basis of analytic methods.
\end{abstract}

KEY WORDS: Judgment; oil spill; analytic methods; energy; environmental risk.

\section{INTRODUCTION}

The importance of judgment in risk assessment is well established. ${ }^{(1-8)}$ Judgment is required to select relevant information from a vast, but incomplete, resource of data about the past and to process that information in order to make an inference about future risk. The necessity for judgment has been blamed for some serious problems of risk assessment including: (a) undue influence of scientists' values and interests on the results, ${ }^{(8)}$ (b) disputes among scientists about risk estimates, ${ }^{(2,4)}$ and (c) the consequent loss of confidence in science. ${ }^{(4)}$ Suggested remedies for these problems have included establishment of a science court, ${ }^{(9)}$ better disclosure of the judgments involved in risk assessment ${ }^{(5)}$ peer review of risk assessments, ${ }^{(10)}$ the use of formal methods for externalizing the parameters of the judgment process, ${ }^{(4)}$ and standardization of risk assessment methods. ${ }^{(10,11)}$

The purpose of this paper is to examine the judgmental basis for risk assessment in an important

\footnotetext{
${ }^{1}$ National Center for Atmospheric Research, P.O. Box 3000, Boulder, Colorado 80307. The National Center for Atmospheric Research is sponsored by the National Science Foundation.

${ }^{2}$ University of Washington, Seattle, Washington 98195.
}

and controversial area of environmental risk - the risk of oil spills from marine transportation associated with proposed coastal energy facilities or offshore oil drilling. We describe three general approaches to the problem-the intuitive, the empirical, and the simulation approaches. We then describe and compare the judgments involved in a number of analytic oil spill risk assessment methods.

\section{OIL SPILL RISK ASSESSMENT}

The threat to marine resources from oil spills has been a major issue in the siting of proposed coastal refineries, oil terminals, and deepwater ports, and in the leasing of offshore lands for oil exploration and development. ${ }^{(12)}$ Risk assessments have been used to estimate both how much oil is likely to be spilled over the life of such projects, and the likelihood that major spills, such as those resulting from the Amoco Cadiz tanker accident, or from the Ixtoc I well blowout, will occur. The questions of the fate of spilled oil and of its impact on important biological or recreational resources have also been components of these assessments. 
Improvements in control technology for oil wells, vessel navigation systems, standards for tanker construction and operations, and training programs designed to reduce the risk of human error have been heavily emphasized in efforts to improve the safety of oil-related activities in the marine and coastal environments. ${ }^{(13)}$ At the same time, oil exploration and development activity has expanded greatly in recent years into harsh environments such as the Arctic Outer Continental Shelf (OCS) and into deeper waters where exploration and development technologies approach the limits of present capabilities. ${ }^{(14)}$

Because historically much larger volumes of spilled oil have been associated with transport than with exploration and production platforms, ${ }^{(12)}$ risk assessments have emphasized the likelihood of transportation accidents. Questions about onshore facility siting, such as the controversial Pittston refinery case, which we discuss below, have focused almost exclusively on the risks associated with tanker accidents.

\section{APPROACHES TO OIL SPILL RISK ASSESSMENT}

There are three general approaches to oil spill risk assessment: the intuitive approach, the empirical approach, and the simulation approach. With the intuitive approach the data and information relevant to the risk are assembled and then an intuitive judgment of the risk is made. The empirical approach relies on the analysis of data about the past. The simulation approach uses a model, usually a computer model or a physical model, which is intended to represent the process underlying the risk. As we will show below, intuitive judgments are the basis for all approaches.

\subsection{Intuitive Approach}

The intuitive approach relies on gathering relevant information, which is then used as the basis for

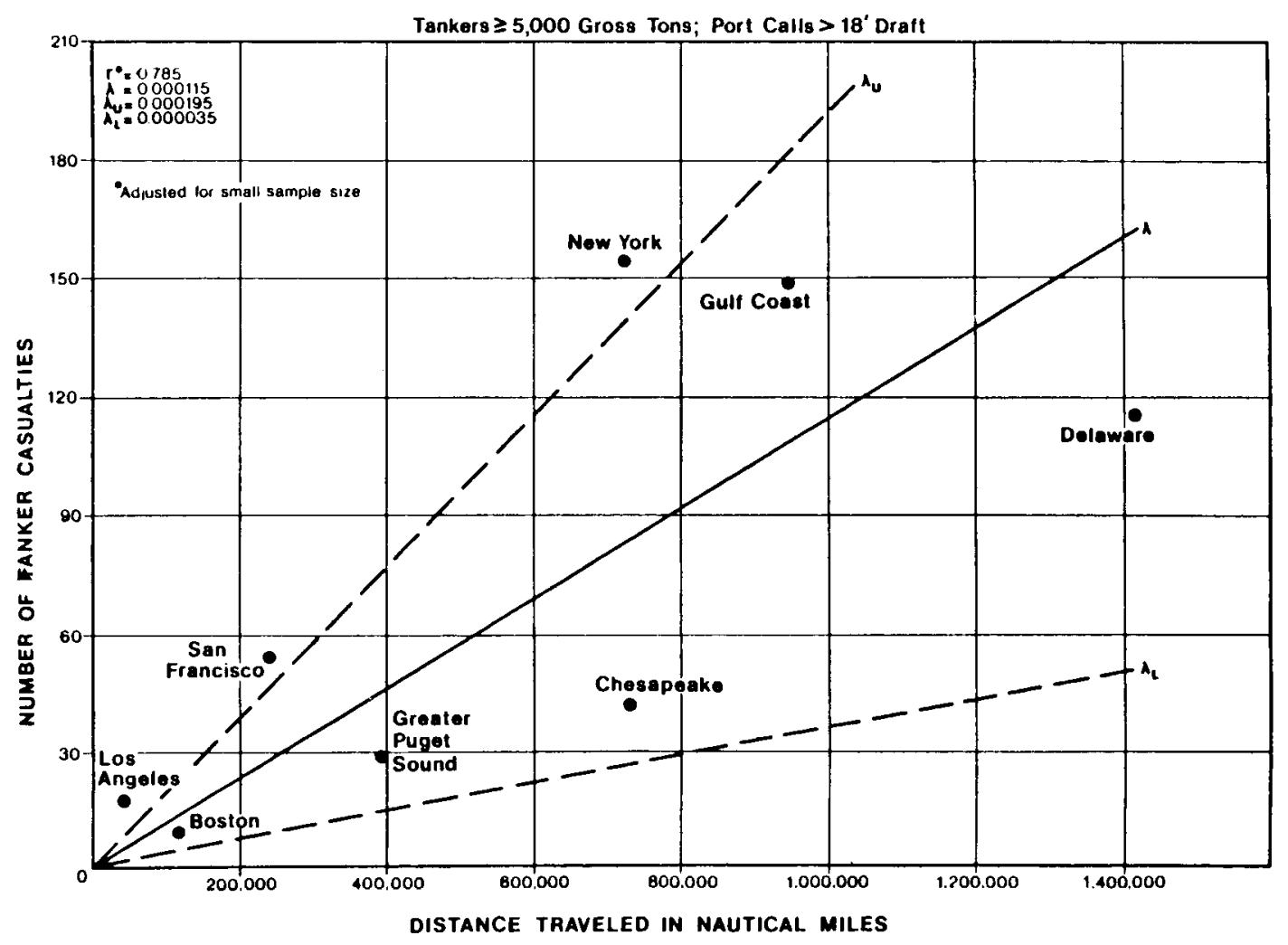

Fig. 1. Tanker casualties vs. distance traveled for eight port systems 1969-1975.(17) 
a judgment of oil spill risks by an expert or by decision makers. The approach is characterized by the presentation of large amounts of information, much of it in a narrative or graphic format, and by the lack of an analytic aid for integrating the information into a judgment. The methods used for selecting and using, information as a basis for judgment are not made explicit. An example of the intuitive approach is the oil spill risk discussion included in the Environmental Impact Statement (EIS) for the refinery proposed by the Pittston Oil Company to be located at Eastport, Maine. ${ }^{(15)}$

\subsection{Empirical Approach}

The typical empirical approach is to develop a model based on a large sample of data, usually from U.S. or world ports, and use that model to predict accidents in a specific port. The three major methods of constructing empirical models are direct projections, regression models, and probability models.

\subsubsection{Direct Projection}

The position paper prepared by the National Oceanic and Atmospheric Administration (NOAA) opposing the Hampton Roads Energy Company's permit application for a 175,000 barrel per day refinery at Portsmouth, Virginia, included an oil spill risk analysis produced by ECO, Inc. ${ }^{(16)}$ the analysis used world and U.S. casualty and oil spill data to estimate the probability of a major oil spill per port call. The maximum number of yearly port calls expected to serve the refinery was then used to estimate oil spill risk. A comparison of Hampton Roads data with world data was presented to support the contention that world data were relevant in this analysis.

\subsubsection{Regression Models}

In its oil spill risk assessment for the Northern Tier Pipeline proposal, the Oceanographic Institute of Washington (OIW) began with an analysis of the historical occurrence of tanker casualties in the eight major tanker ports-of-call in the United States. ${ }^{(17)}$ The number of tanker casualties and the total distance traveled by the tankers in the port were obtained for each port. Figure 1 is a plot of these variables. Regression analysis was used to obtain an equation representing the relation between these variables. This equation was then used to predict tanker casualties in various port/harbor areas within Puget Sound.

\subsubsection{Probability Models}

A method originally developed at MIT in a study sponsored by the Council on Environmental Quality $^{(18,19)}$ has been widely used to predict oil spills associated with offshore petroleum development. This method directly addresses the statistical problems in analyzing oil spill data and attempts to include uncertainty in the analysis. The MIT method includes separate analyses of spill frequencies and spill sizes, and separates large and small spills.

Assumptions are made that allow a complex probability formula to be used to predict oil spill risks resulting from a given level of activity. The estimate is given in terms of a probability distribution that depends upon the projected level of activity, the number of historical observations in the relevant data, and the number of spills observed in the data. An example of the results of this analysis is presented in Fig. 2.

\subsection{Simulation Approach}

Simulation models, based on data, theory, technical expertise and general knowledge, attempt to simulate the most important features of the system used to produce oil or deliver it to ports, and in the processing or transhipment facilities. Such models are meant to reproduce the sequence of events that occurs on trips through a channel or to a port and to simulate the effects of weather, currents, traffic, and other conditions. ECO Inc. conducted a simulation study for Port Valdez, Alaska. ${ }^{(20)}$ A real-time ship simulator was used, and six experienced tanker masters made a number of simulated trips under varying conditions. The results were analyzed to determine the conditions under which safe passage could be made and to estimate the effect of removing a rock outcropping from the channel.

\subsection{Fundamental Decisions in Risk Assessment}

Regardless of the approach taken to oil spill risk analysis, decisions must be made about four areas 

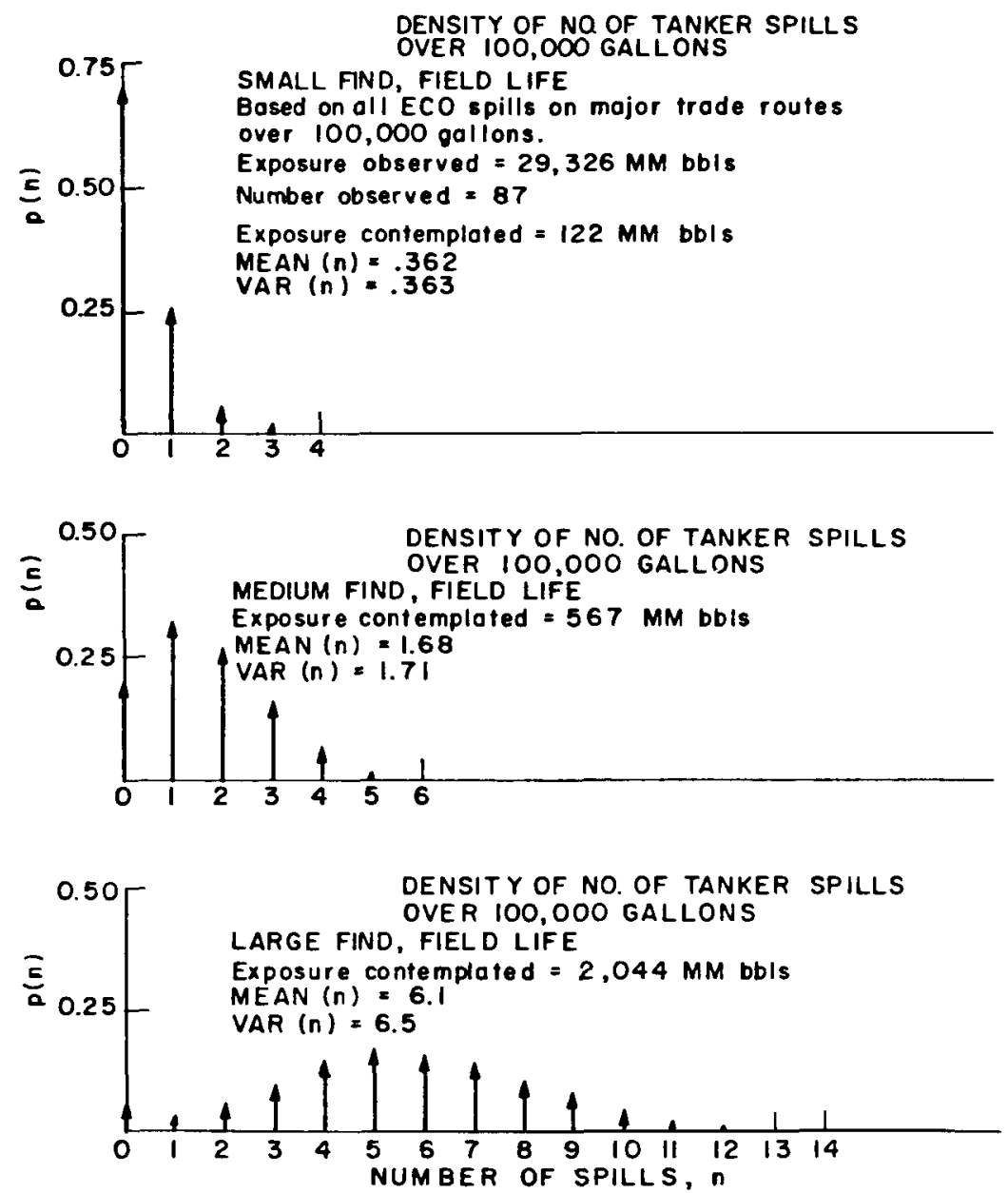

Fig. 2. Example of results obtained using probability models. ${ }^{(18)}$

before the risk assessment process can be completed:

1. Selection of data. What data or information are relevant to oil spill risk?

2. Selection of variables. What variables are the most important determinants of risk?

3. Selection of a functional representation. What are the most representative functional relations among the variables that determine risk?

4. Selection of a representation for uncertainty. How is uncertainty to be incorporated into the assessment?

In the following sections, we will use examples of quantitative oil spill risk assessments (see Table I) to illustrate the judgments involved in each of these decisions. An examination of methods designed to
Table I. Oil Spill Risk Analysis Examples

\begin{tabular}{|c|c|c|}
\hline & Example & Application \\
\hline A. & M.I.T. model & $\begin{array}{l}\text { Widely used in EIS Applications } \\
\text { (e.g., Georges Bank OCS } \\
\text { leasing) }\end{array}$ \\
\hline B. & $\begin{array}{l}\text { ECO Inc. } \\
\text { direct projection model }\end{array}$ & $\begin{array}{l}\text { Hampton Roads Energy Company } \\
\text { refinery, Portsmouth, VA; } \\
\text { Pittston Oil Co. refinery, } \\
\text { Eastport, } \mathrm{ME}^{(16,23)}\end{array}$ \\
\hline C. & OIW regression model & Northern Tier pipeline proposal ${ }^{(17)}$ \\
\hline D. & $\begin{array}{l}\text { NOAA multiple } \\
\text { regression model }\end{array}$ & $\begin{array}{l}\text { Examination of causes of worldwide } \\
\text { tanker casualties } \text { c }^{(24)}\end{array}$ \\
\hline E. & $\begin{array}{l}\text { Navigational } \\
\text { risk index }\end{array}$ & $\begin{array}{l}\text { Siting study for Canadian deep- } \\
\text { water oil ports } \\
(25)\end{array}$ \\
\hline F. & $\begin{array}{l}\text { Judgmental analysis of } \\
\text { waterway safety }\end{array}$ & Northern Tier Pipeline proposal ${ }^{(17)}$ \\
\hline
\end{tabular}


produce quantitative risk estimates will show that the judgments involved in risk assessment can have a profound effect on the results.

\section{JUDGMENTS IN QUANTITATIVE RISK ANALYSIS}

Table I lists six examples of studies that were designed to produce quantitative estimates of the risk of oil spills. Examples A, B, and C used the empirical methods that were described above as illustrations of the probability, direct projection, and regression methods, respectively. Example D used a multiple regression approach to investigate the relative effects of vessel flag, size, and age on the casualty rates of oil tankers from 1969 to 1978.

Examples $E$ and $F$ illustrate a different approach to risk analysis that includes elements of both the intuitive and the simulation approach. In these examples, a simple "rating and weighting" risk model was developed by experts based on their knowledge and experience. The basic procedure consisted of the following steps:

1. List the important factors that contribute to relative navigational risk.

2. Assign a numerical rating to each alternative site or area on each factor.

3. Assign weights to the factors that reflect their relative importance in determining navigational risk.

4. Multiply the ratings by the weights and add up the results to obtain a navigational risk index for each alternative.

This procedure was used by the Canadian Department of Fisheries and Environment in its study of alternative sites for deepwater oil ports (Example E). A navigational risk index was based on seven factors: winds, visibility, currents, water depths, passage widths, course changes, and shipping density. For each factor, a rating scale was developed to translate available data into a navigational risk rating. For example, the system that was used for wind speed is described in Table II.

The result was a set of ratings of the alternative sites on each of the navigational risk factors. Weights for each factor were developed by Department of Fisheries and Environment Staff to indicate the relative importance of each of the factors. The weighted
Table II. A Risk Rating System for Wind Speed

\begin{tabular}{cc}
\hline $\begin{array}{c}\text { Percent of time that } \\
\text { wind speed is greater than or equal to } 24 \mathrm{mph}\end{array}$ & $\begin{array}{c}\text { Risk } \\
\text { rating }\end{array}$ \\
\hline $0 \%-5 \%$ & 1 \\
$6 \%-10 \%$ & 2 \\
$11 \%-15 \%$ & 3 \\
$16 \%-25 \%$ & 4 \\
over $25 \%$ & 5 \\
\hline
\end{tabular}

sum of the ratings was adjusted to a scale of 0 to 100 obtain the navigational risk index. This index was used along with other factors in order to obtain a ranking of sites.

The Oceanographic Institute of Washington (OIW) used a variation of the rating and weighting method in its oil spill risk analysis for the Northern Tier Pipeline Environmental Impact Statement (Example F). Their method, called Judgmental Analysis of Waterway Safety (JAWS) used a panel of experts to assess relative safety of alternative ports within the Puget Sound area. The panel first identified several important "parameters" and "thresholds." An example of a parameter is "cross channel current." For a loaded tanker, the threshold is $2-2.5$ knots. The panel felt that the prudent mariner might become concerned for ship safety when the current was greater than the threshold level. The panel then ranked the alternative sites in increasing order of concern for ship safety. An initial ranking was obtained by averaging the rankings of the panel members.

The OIW analysis also included paired comparison ratings by the panel members of the similarity between alternative sites. Rankings obtained by this method agreed closely with those obtained by the previous method, and analysis of the similarity ratings revealed something of the basis of the preference order.

The following sections compare some of the judgments that were the basis for these analyses.

\subsection{Selecting the Data}

Vast amounts of data with possible bearing on oil spill risk assessment are available from numerous sources. These sources include historical records of casualties and spills, meterological records, coastal maps and nautical charts, shipping records, tanker 
design, and hydrodynamics data. Since no single risk assessment can, or should attempt to make use of all the available data, the analyst must select the data considered most relevant. Generally, the selection of data is strongly influenced by the preferred analytic approach. Empirical studies emphasize data from historical records, while simulation studies emphasize site-specific data obtained from maps, nautical charts, and meterological records, as well as the hydrodynamic properties of tankers. Intuitive approaches may use any data that is judged relevant.

Once the general categories of data are chosen, it may be necessary to select from a number of possible subcategories within that category. For example, historical spill records are available from several sources, including the U.S. Coast Guard, ECO Inc., Lloyds of London, the Tanker Advisory Center, and the U.S. Geological Survey. Furthermore, historical records may be subdivided by date, country, location of spill, and size of vessel involved.
The second column of Table III describes the data used in each of the six quantitative spill risk assessment methods described in Table I. Although similar in general approach, each of the empirical risk assessment methods (A-D) uses a different data set. Since spill rates vary both in time and by location, the choice of data has a significant impact on the results.

Examples of $E$ and $F$ rely on site-specific information. The Navigational Risk Index (E) is based on data obtained from weather records, published information about the port, and shipping records. The JAWS method (F) uses the same kind of data, but obtains it indirectly through the knowledge and judgment of the experts who are involved in the analysis.

The relevance of data to oil spill risk analysis became a major topic of controversy in the review of the proposed Pittston Oil Company refinery at Eastport, Maine. NOAA argued that historical spill

Table III. Comparison of Decisions in Oil Spill Risk Analysis

\begin{tabular}{|c|c|c|c|c|c|}
\hline \multicolumn{2}{|c|}{ Example } & \multirow{2}{*}{$\begin{array}{l}\text { Data used } \\
\text { U.S. Coast Guard pollution } \\
\text { incident reporting system } \\
\text { data for spills in U.S. } \\
\text { waters }\end{array}$} & \multirow{2}{*}{$\frac{\text { Exposure variables }}{\text { Tanker years }}$} & \multirow{2}{*}{ 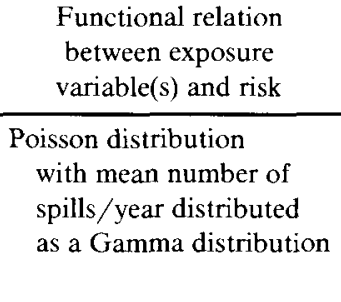 } & \multirow{2}{*}{$\begin{array}{c}\begin{array}{c}\text { Treatment of uncertainty } \\
\text { in relation between } \\
\text { exposure and risk }\end{array} \\
\text { Spill frequencies and volumes } \\
\text { modeled as } \\
\text { stochastic processes } \\
\text { with uncertain parameters } \\
\text { using Bayesian analysis }\end{array}$} \\
\hline & M.I.T. model & & & & \\
\hline B. & $\begin{array}{l}\text { ECO Inc. direct } \\
\text { projection model }\end{array}$ & $\begin{array}{l}\text { Worldwide and U.S. tanker } \\
\text { casualties, 1972-1978 }\end{array}$ & Port calls & $\begin{array}{l}\text { Probability of spill } \\
\text { per port call projected } \\
\text { to compute probability } \\
\text { of one or more spills } \\
\text { per } n \text { port calls }\end{array}$ & $\begin{array}{l}\text { Uncertainty not explicitly } \\
\text { incorporated into } \\
\text { risk estimate }\end{array}$ \\
\hline C. & OIW regression model & $\begin{array}{l}\text { Casualties and distances } \\
\text { traveled at } 8 \text { U.S. ports } \\
1969-1975\end{array}$ & $\begin{array}{l}\text { Distance traveled } \\
\text { by tankers per } \\
\text { port call }\end{array}$ & Linear relation & $\begin{array}{l}\text { Statistical confidence } \\
\text { interval computed for } \\
\text { regression line }\end{array}$ \\
\hline D. & $\begin{array}{l}\text { NOAA multiple } \\
\text { regression model }\end{array}$ & $\begin{array}{l}\text { 1959-1978 worldwide } \\
\text { tanker accident data }\end{array}$ & Tanker years & Linear & $\begin{array}{l}\text { Statistical measures of } \\
\text { significance and strength } \\
\text { of relation }\end{array}$ \\
\hline E. & $\begin{array}{l}\text { Navigational risk } \\
\text { index }\end{array}$ & $\begin{array}{l}\text { Coastal weather reports } \\
\text { published information on } \\
\text { currents, nautical charts } \\
\text { shipping records }\end{array}$ & $\begin{array}{l}\text { Winds, visibility, } \\
\text { currents, } \\
\text { water depth, } \\
\text { channel width, } \\
\text { course changes, } \\
\text { shipping density }\end{array}$ & Weighted sum & $\begin{array}{l}\text { Uncertainty not explicitly } \\
\text { incorporated into risk } \\
\text { estimate }\end{array}$ \\
\hline F. & $\begin{array}{l}\text { Judgmental analysis } \\
\text { of waterway safety }\end{array}$ & Judgments of experts & $\begin{array}{l}\text { Waves, currents, } \\
\text { wind, visibility, } \\
\text { traffic, } \\
\text { channel width, } \\
\text { water depth }\end{array}$ & $\begin{array}{l}\text { Functional relations } \\
\text { implicit in expert } \\
\text { judgment }\end{array}$ & $\begin{array}{l}\text { Uncertainty not explicitly } \\
\text { incorporated into risk } \\
\text { estimate, but may have } \\
\text { had implicit influence } \\
\text { on expert judgment }\end{array}$ \\
\hline
\end{tabular}


rates at New England and world ports could be applied to the Eastport case. The use of historical port data resulted in an "empirically" computed tanker spill probability of .155 per year (based on a New England spill probability of $4.36 \times 10^{-4}$ and a projected 387 tanker port calls per year). The Environmental Protection Agency (EPA), and Pittston, rejected worldwide spill statistics, however, and instead relied heavily on information about operating procedures that the company had promised to use (including tug assistance for tankers, sophisticated radar guidance, and prohibiting tanker passage during adverse weather conditions).

While rejecting the use of historical spill statistics, EPA and Pittston did rely on data from one British port--Milford Haven. That port, which, it was argued, required more difficult tanker maneuvers than the Eastport site would, had a record at the time of 745 safe supertanker port calls. Reliance on data about proposed operating procedures and the analogy to Milford Haven, resulted in the qualitative determination that the Eastport site was "safe."

Each data source used in the Eastport case has limitations. Historical tanker casualty data can be justifiably criticized as not being site-specific. They do no reflect the conditions at Eastport or the way that supertankers will be constructed and operated in the future. Reliance on the company's description of safety procedures can also be criticized because such procedures have not been tried at this site and no one knows how effective they will be or whether they will be implemented as described. For example, how would a tanker master and port captain respond to pressure to bring a loaded crude carrier into port in bad weather when the cost of waiting for good weather could be substantial?

The argument that the Milford Haven experience is relevant to Eastport depends upon a judgment of similarity between these ports and a judgment that the Milford Haven experience demonstrates its safety. There are clear differences between the ports, as noted in the EIS, and furthermore, it can be shown that, given the low probability of spills calculated from worldwide data, the sample size at Milford Haven was not yet large enough to support a determination that that port was safe. ${ }^{(26)}$

Since there are serious objections to all the types of data used by the various parties to the dispute, the data cannot be selected on purely objective grounds. A judgment of the relative seriousness of the different objections is required. In the case of the Pittston refinery, it is possible that another judgment also influenced the data-a judgment of which source of data was most consistent with the party's self-interest. It is probably not an accident that the opponents of the refinery tended to emphasize the use of worldwide spill statistics, which indicated a fairly high probability of a major spill during the life of the refinery, while proponents relied on operations plans and the Milford Haven analogy, which suggested that Eastport could be a "safe" port for supertankers. The potential for the intrusion of "values" into risk assessment has been pointed out by Fischhoff et al. ${ }^{(27)}$ and others.

The Eastport example illustrates a typical dilemma in data selection. Should one use historical records that are "objective" and represent actual events but may not apply to a future where conditions are drastically changed? Or should one rely on information that is site-specific, and operationspecific, but that has an uncertain or unknown relation to risk because of lack of experience with those specific conditions? There is no objective way to choose between these two options, and the choice is one that can have a significant effect on the results.

\subsection{Selecting the Variables}

Most data include a number of variables. For example, worldwide tanker oil spill data can be analyzed by port or by vessel. The port statistics can be analyzed by country, by location of casualty, and by vessel size. Information on site characteristics includes channel width and configuration, currents, climate, composition of bottom, and many other relevant characteristics. The amount of data available, and the resources available to analyze it generally limit the number of variables that can be considered. Since the importance of variables not included in the analysis may never be discovered, the choice of variables is critical.

Perhaps the most important choice of a variable is the choice of an exposure variable. Table IV compares projections of oil spill probabilities for the Pittston refinery under different exposure variables. The range of probabilities is large and, furthermore, there is no objective way to determine which exposure variable, or set of variables, is correct.

Exposure to risk has been measured in a variety of ways by different studies (see Table III). Although the choice of exposure variables has an important 
Table IV. Comparison of Projections for Proposed Pittston Oil Company Refinery Based on Three Different Exposure Variables

\begin{tabular}{|c|c|c|c|}
\hline Exposure variable & Data source & Tanker spills & $\begin{array}{l}\text { Projected probability of } \\
\text { at least one casualty } \\
\text { related oil spill in any } \\
\text { one year of operation of } \\
\text { proposed refinery }\end{array}$ \\
\hline Port calls & Beyer and Painter, 1977 & $.92 / 10^{3}$ port calls & .30 \\
\hline $\begin{array}{l}\text { Volume of petroleum } \\
\text { transported }\end{array}$ & $\begin{array}{l}\text { Beyer and Painter, } 1977 \\
\text { Card, et al., } 1975 \\
\text { Devanney and Stewart, } 1974\end{array}$ & $\begin{array}{l}12 \text { spills } / 10^{9} \text { bbl } \\
8 \text { spills } / 10^{9} \mathrm{bbl} \\
3.4 \text { spills } / 10^{9} \mathrm{bbl}\end{array}$ & $\begin{array}{l}.88^{a} \\
.75^{a} \\
.44^{a}\end{array}$ \\
\hline Distance travelled & $\begin{array}{l}\text { Oceanographic Inst. } \\
\text { of Washington, } 1978\end{array}$ & $\begin{array}{c}.033 \text { spills } / 1000 \text { miles } \\
\text { of tanker travel }\end{array}$ & $.10^{b}$ \\
\hline
\end{tabular}

${ }^{a}$ Assumes 174 million bbl/year of product and crude transported by tanker.

${ }^{b}$ Assumes 87 VLCC trips 7 miles from Head Harbor Light to Broad Cove, and 300 product tanker round trips 8.1 miles from Head Harbor Light to Deep Cove. This figure does not include coastal spills that might occur outside of Head Harbor Light.

effect on results, the choice is generally not explicitly justified in applications, nor are different exposure variables used in order to investigate the sensitiviry of the results to the exposure variable.

The appropriate exposure variables depend upon the type of event being predicted and on how that event is expected to occur. For example, if one is interested in predicting spills caused by vessel collisions, then a measure of exposure might be the number of ship-hours spent underway within a specified close distance from other ships. ${ }^{(28)}$ Alternately, the number of miles traveled in close proximity to other ships might be used. Unfortunately, data on these exposure variables is not readily available, so surrogate variables, such as the number of tanker port calls, have been used. The suitability of such variables is a matter of judgment.

Beyer and Painter ${ }^{(28)}$ suggest two tentative criteria for selecting an exposure variable: "historical spill data should indicate a functional relationship with the variable, and the variable should be capable of distinguishing between the spill potentials of project alternatives requiring a decision" (p. 21). These criteria may reduce the size of the set of candidate exposure variables, but there will generally be more than one exposure variable that meets both criteria. Additional criteria will be necessary, therefore, to make the final selection of an exposure variable. Because of the limited understanding of the causes of oil spills and the limited availability of data, these criteria and the tradeoffs among them are currently left to the analyst's judgment.

\subsection{Selecting Functional Forms}

Selecting the form of the functional relations among variables is fundamental to all risk analyses. In intuitive risk analyses, the functional forms implicit in judgments of risk are not clearly stated. In empirical approaches, functional forms are assumed in certain curve fitting and estimation procedures. Within the empirical approach it is possible to compare several different functional forms with regard to their ability to fit the data. However, functional forms which fit past data equally well can produce quite different projections. In simulation approaches, functional forms, based on assumption, theory, or data, are built into the computer model.

The most important functional relations in oil spill risk analysis describe the relation between the exposure variables and risk. The fourth column of Table III shows the variety of such functional relations used in the six examples. Functional relations range from the sophisticated probability functions of the M.I.T. method to simple linear relations. In the JAWS approach, as in the purely intuitive approach, the functional relations are implicit in the judgments of risk.

The choice of functional forms requires tradeoffs that involve judgment. A common tradeoff is between methodological and mathematical sophistication on the one hand, and simplicity and availability of data on the other. Although sophisticated functional forms seem to be required to capture the complexities of the real-world process that is being 
represented, the data required to fit these forms are often not available. As a result, assumptions based on judgment are required. For example, in the M.I.T. example (A) and its subsequent applications, it is assumed that spill frequencies are governed by a Poisson process. The principal support for this assumption is its simplicity (discrete, independent, Poisson distributed random events) and that the Poisson process has some attractive analytical properties. It is difficult to imagine this assumption receiving the kind of public debate and scrutiny that it might deserve; yet recent studies have cast some doubts on its validity. ${ }^{(29)}$

The simpler functional forms, notably the linear, are easily fit to existing data and readily understood and interpreted, but they ignore the nonlinearities in the relations among variables. Whether those nonlinearities can be safely ignored, or whether the gain in clarity of analysis offsets the failure to capture the complexities that determine oil spill risk, is a matter for judgment.

\subsection{Selecting a Method for Dealing with Uncertainty}

Since estimates of the probability of oil spills are inherently uncertain, the analyst must decide how to deal with that uncertainty. One way to do this is to simply report a point estimate, a "best guess," and leave it at that. In this case, the users of the results must estimate the uncertainty. Another way to deal with uncertainty is to attempt to make it explicit and to report uncertainty along with the estimate.

The last column of Table III summarizes the methods for dealing with uncertainty that were used in the six oil spill risk analysis examples. Three of the cases attempted to make uncertainty explicit. The M.I.T. model uses probability theory to derive probability distributions for both numbers and sizes of spills. Two other methods (C and D) use classical statistical measures of uncertainty in estimates of population parameters from samples. The other three methods make no attempt to measure the uncertainty in their estimates.

Once the decision has been made to treat uncertainty explicitly, additional judgments are required to select an underlying statistical distribution to represent historical spill frequencies or volumes. In applying a Bayesian approach to modeling the distribution of oil spill frequency and volume, Stewart and Devanney ${ }^{(21)}$ have noted several problems in the historical data that compromise the investigator's ability to distinguish among candidate models. They note, for instance, that the U.S. Coast Guard Pollution Incident Reporting System (PIRS) data contains numerous errors, that incidents of groundings and collisions are too few for accurate modeling of the process involved, and that the data may be biased both by censoring and by selective underreporting of small spills. ${ }^{(21)}$ Thus, the analyst faced with the task of estimating from the historical record the probability that spills in certain size classes or from certain causes will occur must necessarily make a number of judgments in modeling the uncertainties.

\section{CONCLUSION}

The examples we have given illustrate the diversity of methods used in oil spill risk assessment and the inherently judgmental basis of these methods. More examples could have been drawn from oil spill risk studies and similar examples could be found for almost any type of risk analysis. The lesson of these examples is that judgments are inevitably involved in the choice and implementation of a risk assessment method. The use of analytic methods is not an antidote for judgment. Such methods merely change the locus of judgment, replacing one kind of judgment with another. This lesson is not a comforting one for decision makers whose responsibility it is to determine risk before permitting a major project, or licensing a chemical or food additive.

Since judgment cannot be eliminated from risk assessment, the limitations and biases of the judgment process should be of particular concern to those who produce and use such assessments. For example, judgments, and hence the results of analyses, may be influenced by the interests and values of those who conduct or sponsor the analysis. ${ }^{(20,30,31)}$ Risk assessments require judgments about complex, poorly understood systems, and research on the human judgment process suggests that such judgments exceed human cognitive capacity (see Refs. $32-34$ for reviews of human judgment research). Furthermore, the judgment process is subject to a number of biases, particularly when statistical reasoning is required. ${ }^{(35)}$ Fischhoff and Whipple ${ }^{(3)}$ have argued that such biases may limit the validity of risk judgments.

Perhaps the most serious problem introduced by dependence on judgment is that the reasons for 
conclusions are implicit; they are not open to public or expert scrutiny. The danger of not making the basis for judgments explicit is that the numerous limitations and sources of error and bias in judgment may influence important decisions, yet remain undiscovered. Judgments are particularly susceptible to extraneous influences, such as the manner of presentation of information, and to invalid inferences, such as misconceptions of chance.

As we noted in the introduction, several remedies have been proposed for the problems introduced by the need for judgment in risk assessment. Perhaps one of the least appropriate remedies proposed is the premature standardization on a single method of risk assessment. ${ }^{(36)}$ Although this approach may temporarily resolve the decision maker's dilemma by providing a single, agreed-upon risk estimate for decision-making purposes, it does not guarantee the validity of such an estimate. Indeed, improving the validity of risk estimation requires just the opposite procedure; the widest possible range of risk estimates should be developed. Understanding the risks requires an understanding of the differences among different estimates. Use of only one method produces only ignorance of other alternative methods and a false sense of certainty about the level of risk.

Some potentially useful aids for overcoming the biases and limitations of judgment have been developed by researchers in the field of judgment and decision making. These aids help make the parameters of the judgment process more explicit so that the basis for judgments can be subjected to critical examination. Some aids also make it easier to cope with complex judgment problems involving many interacting variables, and uncertainty. For an overview of such aids, see Hammond et al. ${ }^{(37)}$ and Hogarth. ${ }^{(33)}$ Fischhoff ${ }^{(38)}$ discusses such aids in the context of risk analysis. Hammond et al. ${ }^{(4)}$ provide an excellent example of the use of judgment aids in an assessment of cancer risk. Once the judgmental foundation for risk assessment is clearly recognized, systematic methods developed through judgment and decision research can be used to improve the process.

\section{ACKNOWLEDGMENTS}

The authors wish to thank Mary Downton, Dale Jamieson, Maria Krenz, and Robert J. Stewart for helpful comments on an earlier version of this manuscript, and Jan Stewart and Bev Chavez for typing and word processing the manuscript through its many revisions.

\section{REFERENCES}

1. S. Cotgrove, "Risk, Value Conflict, and Political Legitimacy," in R. F. Griffiths (ed.), Dealing with Risk (Wiley, New York, 1981).

2. R. B. Cumming, "Risk Assessment and the Governmental Policy-Making Process," Risk Anal. 3, 1-3 (1983).

3. B. Fischhoff and C. Whipple, "Risk Assessment: Evaluating Error in Subjective Estimates," The Environmental Professional 3, 277-291 (1981).

4. K. R. Hammond, B. F. Anderson, J. Sutherland, and B. Marvin, "Improving scientists' Judgments of Risk," Risk Anal. 4, 69-78 (1984)

5. W. W. Lowrance, Of Acceptable Risk (Kaufman, Los Altos, California, 1976)

6. A. P. Sage and E. B. White, "Methodologies for Risk and Hazard Assessment: A survey and Status Report," IEEE Transactions on Systems, Man, Cybernetics 10, 425-446 (1980).

7. R. O. Smalley, "Risk Assessment: An introduction and Critique," Coastal Zone Management Journal 7, 133-162 (1980).

8. A. S. Whittermore, "Facts and Values in Risk Analysis for Environmental Toxicants," Risk Anal. 3, 23-33 (1983).

9. A. Kantrowitz, "Controlling Technology Democratically," American Scientist 63, 505-509 (1975)

10. National Research Council, Committee on the Institutional Means for Assessment of Risks to Public Health, Risk Assessment in the Federal Government: Managing the Process (National Academy Press, Washington, D.C., 1983).

11. Nuclear Regulatory Commission, Action Plan to Implement the Commission's Proposed Safety Policy Statement (Draft Revision), (Enclosure 1 to memorandum from W. Dircks to the NRC dated July 6,1982, cited in Apostolakis et al., 1983).

12. National Academy of Sciences, Petroleum in the Marine Environment (National Academy Press, Washington, D.C., 1975).

13. National Academy of Sciences, Safety and Offshore Oil (National Academy Press, Washington, D.C., 1981).

14. W. L. Lahey and T. M. Leschine, "Evaluating the Risks of Offshore Oil Development," Environmental Impact Assessment Review 4 (3-4), 271-286 (1983).

15. Environmental Protection Agency, Proposed Issuance on Federal permits to the Pittston Company of the New York for the Construction of a 250,000 Barrel / Day Oil Refinery and Marine Terminal, (Final Environmental Impact Statement Eastport, Maine, 1978)

16. Engineering Computer Optecnomics (ECO), Inc., The Proposed Oil Refinery at Eastport, Maine - A Preliminary Oil Spill Risk Assessment of Marine Operations (prepared for the Office of Habitat Protection, National Marine Fisheries Service, NOAA, June 1979)

17. Oceanographic Institute of Washington (OIW), Oil Spill Risk Analysis for the Federal Northern Tier Pipeline Environmental Statement (prepared for the Bureau of Land Management, October 1978).

18. J. W. Devanney and R. J. Stewart, Analysis of Oil Spill Statistics (MIT Sea Grant Program Report No. MITSG 74-20, 1974).

19. J. W. Devanney and R. J. Stewart, "Bayesian Analysis of Oil Spill Statistics," Marine Technology 11, 365-382 (1974).

20. V. F. Keith, J. D. Porricelli, J. P. Hooft, P. J. Paymans, and F. G. Witt, Real-Time Simulation of Tanker Operations for the Trans-Alaska Pipeline System (Paper presented at the annual 
meeting of The Society of Naval Architects and Marine Engineers, New York, November 1977).

21. R, J. Stewart and J. W. Devanney, "Estimating Tanker Spill Risks in U.S. Waters," Proceedings of the Business and Economics Section, American Statistical Association, 464-469 (1978).

22. R. J. Stewart and M. B. Kennedy, An Analysis of U.S. Tanker and Offshore Petroleum Production Oil Spillage Through 1975 (A report to U.S. DOI under contract No. 14-01-0001-2193 from Martingale, Inc., Cambridge, Massachusetts, 1977).

23. Engineering Computer Optecnomics (ECO), Inc., Proposed Hampton Roads Refinery-An Assessment of Oil Spills Associated with the Marine Operations (prepared for Office Habitat Protection, National Marine Fisheries Service, NOAA, December 1978).

24. N. F. Meade, T. LaPointe, and R. Anderson, "Multivariate Analysis of Worldwide Tanker Casualties," Proceedings of the 1983 Oil Spill Conference (American Petroleum Institute, Washington, D.C., 1983), pp. 553-557.

25. "Fisheries and Environmental Canada," Potential Pacific Coast Oil Ports: A Comparative Environmental Risk Analysis (February 1978).

26. T. R. Stewart, Testimony before the Environmental Protection Agency for the National Oceanic and Atmospheric Administration and The New England Fishery Management Council on Navigational Risk Analysis for the Proposed Oil Refinery at Eastport, Maine, (November 1979).

27. B. Fischhoff, S. Lichtenstein, P. Slovic, S. L. Derby, and R. L. Keeney, Acceptable Risk, (Cambridge University Press, Cambridge, 1981).

28. A. H. Beyer and L. J. Painter, "Estimating the Potential for
Future Oil Spills from Tankers, Offshore Development, and Onshore Pipelines," Proceedings of the 1977 Oil Spill Conference (sponsored by the American Petroleum Institute, 21-30).

29. A. Nakassis, Has Offshore Oil Production Become Safer? (U.S. Geological Survey Open-File Report, 32-232, 1982).

30. K. R. Hammond and L. Adelman, "Science, Values, and Human Judgment," Science 194, 389-396 (1976).

31. T. R. Stewart, R. L. Dennis, and D. W. Ely, "Citizen participation and Judgment in Policy Analysis: A Case Study of Urban Air Quality Policy," Policy Sciences 17, 67-87 (1984).

32. H. J. Einhorn and R. M. Hogarth, "Behavioral Decision Theory: Processes of Judgment and Choice," Annual Review of Psychology 32, 53-88 (1981).

33. R. M. Hogarth, Judgment and Choice: The Psychology of Decision (Wiley, Chichester, England, 1980).

34. P. Slovic, B. Fischhoff, and S. Lichtenstein, "Behavioral Decision Theory," Annual Review of Psychology 28, 1-39 (1977).

35. D. Kahneman, P. Slovic, and A. Tversky (eds.), Judgment Under Uncertainty: Heuristics and Biases (Cambridge, University Press, New York 1982).

36. G. Apostolakis, B. J. Garrick, and D. Okrent, "On Quality, Peer Review, and the Achievement of Consensus in Probabilistic Risk Analysis," Nuclear Safety 24, 792-800 (1983).

37. K. R. Hammond, G. H. McClelland, and J. Mumpower, Human Judgment and Decision Making: Theories, Methods, and Procedures Praeger, (New York, 1980).

38. B. Fischhoff, "Judgmental Aspects of Risk Assessment," to appear in Handbook of Risk Assessment (prepared by the National Science Foundation for the Office of Management and Budget, in press). 